\title{
The Impact of Information Technology on Knowledge Management Processes
}

\section{An Empirical Study in the Arab Potash Company}

\author{
Sattam Allahawiah $^{1}$, Hisham Al-Mobaideen ${ }^{2} \&$ Kafa al Nawaiseh $^{1}$ \\ ${ }^{1}$ Department of Managerial and financial sciences, Albalqa Applied University, Jordan \\ ${ }^{2}$ Department of Management Information Systems, Mu’tah University, Jordan \\ Correspondence: Sattam Allahawiah, Albalqa Applied University, Jordan. Tel: 962-79-516-9812. E-mail: \\ Sattam.amro@yahoo.com
}

Received: November 12, 2012

Accepted: December 17, 2012 Online Published: December 20, 2012

doi:10.5539/ibr.v6n1p235

URL: http://dx.doi.org/10.5539/ibr.v6n1p235

\begin{abstract}
This Study aims to identify the impact of IT on Knowledge management processes in the Arab Potash Company, to achieve the goals of this study a questionnaire were developed for the purpose of Data Gathering, The study sample contained (336) respondents, A group of results were reached; Mainly the following: there is an impact of IT in using Knowledge as a dimension of Knowledge Management processes in the Arab Potash Company, this explains that the Company was keen to employee technology in most of its business to achieve work speed and getting the proper information using modern machines and networks achieving its goals, the dimensions of technology explains (48.7\%) of the variation of Knowledge Management processes. The study recommended the need for Potash Arab Company to take the role caring about the properties dimensions of IT, and emphasize it as it can improve performance, Employee Satisfaction, and improve the level of Knowledge employment, and the importance of getting employers and users involved in the process of designing Information System and developing it; as it carries a lot of importance in self-satisfaction, and it build a management philosophy and organizing method supports the implementation of Knowledge Management by the top management, also provides a level of the top management commitment in the embodiment of Knowledge Culture among the workers, developing their skills, and provides a strategically vision with a clear monuments to the organization and its goals.
\end{abstract}

Keywords: characteristics of information technology, knowledge management processes, Potash Arab Company, Information Technology (IT)

\section{Introduction}

The Subject of using IT is one of the essential issues that researches seeks to shade some lights on as well as studying it from various angels, in order to enrich it and make use of the study and research results to develop its applications in the various business organizations. The employment of IT among Managerial organization involves making essential changes in all its managerial system that affect Human resources as in technical skills, Basic of the work implementation, organizations policies, and the Leader behavior which plays the main rule in its success, regardless of the work difficulty that workers face (Laudon \& Laudon, 2007: 65), and in order for the organization to move forward in future, it has to employee technology, which is a mandatory need for those organization that's seeking excellence in performance.

With the technology revolution and increased competition organizations starts to realize slowly the importance of technology and its role as an activity that can be organized, and systematic; for proper knowledge Employment (Omari, 2004), and to the importance of knowledge and its role in order to reach services, and new methods achieve better performance. (Najm, 2005). Perhaps the use of these organizations for information systems efficiently and effectively would achieve its goals, it has increased interest in these systems as they play a crucial role in the development of organizations providing all appropriate information in times most suitable for the various administrative levels, in order to support all the functions and administrative functions in addition improvement and the development of communications traffic and the flow of information between those levels, all of which would be reflected positively on the overall performance (Yassin, 2007: 50). 
The talk about the benefits of knowledge management confirms that the organization really need these systems to carry out their activities and their effectiveness in order to achieve the goals they want to achieve in all administrative levels. Even the different organizations can employ knowledge utilize optimally and achieve organizational efficiency must develop its various function, style, working methods and performance to suit the nature of the work of these organizations. As a result of the tremendous scientific expansion in the areas of information systems technology (Quintas, et al., 1997) .Given the importance of information technology in the knowledge management, it has become of particular importance at the Applied level, in order to straighten and control processes of change and development within the various organizations, The importance clearly shown; through the efforts of business organizations; to employ knowledge management as much as possible in development processes, and organizational change in these organizations (Alwaleed, 2009: 171). Hence this study seeks to measure the impact of the characteristics of information technology on knowledge management processes in the Arab Potash Company, the importance of technology leads to effective employment of knowledge.

\subsection{Problem Statement}

The Study Concentrates on failure to recognize the nature of the relationship between the characteristics of information technology and Knowledge Management processes, given the importance of the role played by information technology and one of the threads of living and contemporary in the recruitment and use of knowledge management in the development processes and change, it stayed still away from the progress , success, and excellence, This has made departments generally not ready to enable its members to pursue progress and development of organizations, especially when the information technology require individuals with mentality skills and creative, to achieve that we must develop an organizational culture characterized by experimentation and daring decision-making, the pursuit of creativity and innovation as well as a complete knowledge of the work and its requirements. There are many factors that affect and emphasizes the necessity of adopting information technology, such as technological development, competition, the desire to improve working and poor recruitment knowledge and others, leaving traces and different results on organization; therefore the problem of the study is to measure the impact of IT on knowledge management processes in the Arab Potash Company.

\subsection{The Importance of the Study}

The importance of this study comes from caring about users, with the attention mostly be focused on information technology, and physical components, Since this study concerned with using information technology, that makes this study is gaining a new dimension in the study of ways to develop information systems in the organization, The importance of this study comes from looking at the characteristics of information technology and its impact on the knowledge management processes in the Arab Potash Company, this study take it is important through the following:

Being addressed to one of the organizational concepts which is using information technology, And that is one of the important topics in modern management, Being an important source of the survival of the organization and continuity, especially in companies that seek to adopt modern management strategy that allows the workers making the decisions, take advantage of opportunities, increase their competitiveness, and creativeness. Since this concept (information technology) is a relatively recent in the environment, so the subject of this concept applied to study gives clear importance within the scientific framework for advanced management methods in the acquisition of knowledge and skills, and be used to improve performance and increase productivity.

The importance of this study comes from the importance of adopting information technology in the Arab Potash Company; since the use help in the adoption of new working methods differ from typical traditional work, helping them solve their problems and embrace change as a method. Also, this study can draw the attention of managers and decision-makers in the Arab Potash Company to the importance of adopting the use of management information system technology in order to strengthen them as well as help in the proper employment of knowledge. This study contributes to enriching the Arab library with new topic that is may be of interest to researchers and practitioners, and is the starting point for further studies.

\subsection{The Objectives of the Study}

This study aims mainly to analyze and measure the impact of information technology on knowledge management processes in the Arab Potash Company and emerge from this goal the following objectives:

- Recognize the reality of the use of information technology and employ knowledge management in the Arab Potash Company. 
- Test the impact of the use of information technology (hardware, software, security, and Usability) and knowledge management processes in its various dimensions (knowledge creation, knowledge acquisition, organization of knowledge, the knowledge sharing, knowledge implementation).

- Provide a conceptual framework on the subject of the use of information technology and knowledge management processes in the Arab Potash Company.

- Make recommendations based on the results of the study will help decision makers to adopt the use of information technology as a way of contributing to the success of organizations to improve the recruitment of knowledge management in the development and regulation processes.

\section{Literature Review}

\subsection{Literature Review}

The survey results and previous studies indicated the lack of studies, upon the knowledge of the researchers looking directly at the impact of the characteristics of information technology on knowledge management processes, so this study tried to employ what came in previous studies as much as possible, and where it is possible to achieve their goals, note that the field studies in the Arab environment and Jordan, have been limited:

So in a study carried out by (Alzeriqat, 2010) entitled "The impact of knowledge management on the effectiveness of decision-making in the Jordanian public shareholding companies," The aim of this study was to investigate the impact of knowledge management on the effectiveness of decision-making, and to achieve the goal of the study questionnaire was designed, developed for the purpose of data collection and distribution to members of the study sample, totaling (443) The study reached a number of results where the most important results are:The results indicated that the respondents' perspective to the variable of knowledge management was high at (3.60), and there was an impact on the dimensions of knowledge management on the effectiveness of decision-making, and knowledge management interpreted (59.4\%) of the variance in after (the effectiveness of decision-making).

The study of (Saadi, 2010) entitled "Effect of Information Technology on the audit profession in the corporate industrial sector's in Jordan: An Empirical Study," where the aim of this study was to investigate the views of auditors in industrial companies. study sample consisted of auditors who work in industrial companies numbering (50) auditors, the questionnaire was distributed to them to find out their views on the use of computers in the field of planning, implementation and control and show there is a trace of the use of information technology in the planning, implementing the lack of impact in the use of information technology in censorship.

The study conducted by (Almaani, 2009) entitled "Trends of Managers in Jordanian ministries centers to the role of knowledge management: An Empirical Study" This study aimed to identify the trends of managers in Jordanian ministries centers around the application of the concept of knowledge management and its impact on their job performance, and test differences in those trends depending on the different demographic characteristics, included in the study (260) director in ministries centers. One of the most important results of the adoption of Jordan Ministries concept of knowledge management moderately, that the respondents feel a high level of functionality. And the existence of a statistically significant effect for the following elements of knowledge management: (knowledge generation, team knowledge, knowledge storage, sharing of knowledge, the application of knowledge, and technology and knowledge). On the level of functionality that respondents feel, as interpreted variable knowledge management $40.9 \%$ of the variation in the level of job performance, according to the value of the coefficient of determination R2. And the existence of differences of statistical significance in the trends of the respondents towards the adoption of Jordanian ministries of the concept of knowledge management due to their demographic characteristics with the exception of a variable length of service. The study also showed no statistically significant differences in the attitudes of respondents towards the level of job performance due to their demographic characteristics with the exception of the period of service.

The (Trtarh, 2006) study entitled: "The impact of computerized management information systems and human resource management functions in public institutions in Jordan: An Empirical Study." The purpose of this study was to identify the impact of the use of computerized management information systems with its various dimensions on human resource management functions in public institutions in Jordan. The study sample consisted of (206) individuals make up groups of managers and heads of departments in seven independent public institutions in Jordan. The study found that there is impact for each of the efficiency of the staff working in the Department of Management Information Systems, the quality of the devices used in the computerized information systems, and appropriate information computerized information system on human resources 
management functions: (recruitment, training, and performance evaluation) in public institutions in Jordan.

(Omari, 2004) study entitled: "joint use of information technology and knowledge management to achieve high value to the work of Jordanian commercial banks." This study aimed to analyze the joint use of information technology and knowledge management to achieve a high competitive advantage for the work of Jordanian commercial banks, data were collected from (116) director, an expert, and consultant working in the (16) Jordanian commercial banks, via questionnaire was designed as a tool to measure the form. The study found a number of important results: the presence of a strong relationship and correlation between knowledge management and high value of banking business, and clarity of the direct influence to increase business value in the banks as a result of shared use of information technology and knowledge management, as well as the existence of significant differences between banks in the high value of its work and its use of information technology and knowledge management.

The study conducted by (Adam, 2010) entitled "availability of knowledge management dimensions and its impact on organizational development from the standpoint of administrative staff in government hospitals in the city of Riyad in Saudi Arabia," aimed to identify the availability of knowledge management dimensions and its impact on organizational development from the standpoint of administrative staff in government hospitals in the city of Riyad in Saudi Arabia, to achieve the objectives of the study questionnaire was developed for the purpose of data collection, study sample consisted of (420) the study found a set of results was highlighted:

Those perceptions of workers in government hospitals in the city of Riyad for knowledge management came moderate.

The presence of the effect of knowledge management in organizational development, the dimensions of knowledge management explain the amount of (62.3\%) of the variance in organizational development.

The study conducted by (Aesan \& Ani, 2008) entitled: "The role of information technology in the knowledge management in the College of Education at Sultan Gaboos University." The purpose of this study was to clarify the role of information technology in the knowledge management in the College of Education at Sultan Qaboos University from employees' perspectives. Questionnaire was prepared for the purpose of data collection and distributed to a sample of (93) representatives (62\%) of the total community. The results showed that the arithmetic mean of the level of knowledge management in the College of Education came with a "high" approval, as results showed that there are differences of statistical significance level $(\alpha=0.05)$ between the responses of study sample due to the variable Job Title on the element structure, but for the qualification variable in the use of computers was qualified for a class to learn self. While the results showed no statistically significant differences between the responses of study sample attributable to variables of type, qualification, academic rank, and the number of years of experience in the use of computers.

The (Atwi, 2008) a study entitled "The availability of jobs of knowledge management and its impact on organizational effectiveness among workers in the General Organization for Technical Education and Vocational in Saudi Arabia" aimed to identify the availability and functionality of knowledge management and its impact on organizational effectiveness among workers in the Public Institution for Education Technical and vocational education in Saudi Arabia, and to achieve the objectives of the study he designed and developed a questionnaires for data collection, have been using simple random sampling method to determine the study sample, and reached the sample (371) Single, the study found a number of results, most notably:

Knowledge management processes according to the perceptions of the study sample was of average level. The dimensions of the effectiveness of the institution according to the perceptions of the study sample with a medium level. The presence of the impact of the dimensions of knowledge management processes in organizational effectiveness, and that the dimensions of knowledge management processes explain $(68.7 \%)$ of the variance in organizational effectiveness.

In a study carried out by (Altaweel \& Rasheed, 2005) study entitled: "The impact of information technology in knowledge management processes: a field study in a sample of industrial companies in the province of Neenawa." The purpose of this study was to build a conceptual framework and field to determine the impact of information technology in knowledge management processes in a sample of industrial companies to contribute to the Neenawa province in Iraq. To achieve the objectives of the study a questionnaire were developed, and distributed to a sample consisting of (64) individual who are heads of departments, and members of boards, directors and managers in the surveyed companies formations. The study found a set of conclusions the most important is having a significant effect between information technology and knowledge management processes in companies surveyed, and knowledge management processes, all is not derived efficiency from software and the hardware and also equipment did not contribute positively to the processes of diagnosis knowledge and 
define its objectives.

Hussein conducted a study (Hussain, 2010) entitled: "Knowledge management in small and medium-sized enterprises in developing countries." The objective of this study is to reach the state of knowledge management in small and medium-sized enterprises in developing countries, as well as test the factors that affect the adoption of knowledge management in small and medium-sized enterprises in developing countries. Although there are many organizations have realized the importance of knowledge management in business growth and development, but the results of the study indicated that small and medium-sized enterprises in developing countries did not realize this importance. The study took the lack of attention this into consideration and suggested a particular input to knowledge management in small and medium-sized enterprises in developing countries.

Also Aguior (Aguior, 2009) study entitled: "Application of knowledge management in the field of research and development in the pharmaceutical industry." This study aimed to explore the trends managers pharmaceutical companies in America about knowledge management. Results of the study showed that the use of means and methods of knowledge management increases participation to know, also it showed that knowledge management contributing to the increase in the commercial value of the Pharmaceutical Industry.

The Singh (Singh, 2008) a study entitled: "investigate and develop comprehensive model to understand knowledge management." This study aimed to develop theoretical comprehensive model in understanding of knowledge management in (72) of the Canadian, Indian and American companies. Study found that knowledge management applied in business lines contributed to the knowledge that each stage of production in line with their specific goals and fit in with the evolution of knowledge.

In a study of Oliver (Oliver, 2008) entitled: "knowledge management practices to support the continuous development." The purpose of this study was to find out knowledge management practices with regard to the operations, data were collected by postal survey of Australian organizations that possess the ISO9000 standard. The study results showed that the organizations most successful has provided guidance and recommendations in sharing (experiences, progress projects, best practices, success, failure), as well as the sharing of experiences acquired from the general environment, and finally take advantage of the organizational structure that could facilitate communication between employees.

Akhavan, et al. (2006) study entitled: "Critical Success Factors for knowledge management systems: multi-case analysis." This study aimed to a statement that the critical success factors for the design and application of knowledge management did not achieve an orderly, and that most of the previous studies and the current miss critical success factors from the perspective of the individual organization, and did not take into account all the factors in an integrated manner, as well as the aim of this study is to bridge this gap The study was conducted in (6) international companies in different countries. The results showed that the critical success factors were appropriate for organizations surveyed, and the study concluded (16) concept shows critical success factors, namely, (strategic knowledge, training programs, and support and commitment, and restructuring the company, and the network of experts, and participate with the knowledge, organizational culture, leadership, and storage of knowledge , auditing knowledge, architectural knowledge, organizational structure, transparency, the acquisition of knowledge, the definition of knowledge, and confidence) can be represented in the list of the organization, helps when you want to adopt knowledge management to ensure coverage of all the factors necessary during the implementation phase and design, as well as the study found a conceptual framework shows how to design and implement of knowledge management in the organization, this study also provided a common language for academics to discuss and study the factors critical to the success of knowledge management programs in the organization.

The study of (Kumar \& Kumar, 2006) entitled: "knowledge management based on information technology in the higher education system in India: addressing the quality of the business and determine the right priorities." This study aimed to try to consider knowledge management based on information technology as a management tool to evaluate the technical work in institutions of higher education in India. Have been discussing various possible means in order to make a knowledge management based on information technology impact in the Indian education system, the statistical method was used to analyze the data collected from educational institutions in different regions in India. The results of the study indicated that knowledge implementation management based on information technology not only leads to better quality of services, but to lower the costs of higher education in India.

\subsection{What Distinguishes the Current Study from Previous Studies}

The current study complements the previous studies that dealt with information technology and knowledge 
management, but the current study differ from previous studies especially Arab ones, the previous studies focus on information systems with knowledge management as the study of (Aasan \& Ani, 2008) and (long \& Rashid, 2005), but the current study addressed IT management information systems with the knowledge management processes, this study came to include four variables of the characteristics of information technology (hardware, software, security, and Usability) while the previous studies mentioned some of them, so this study is the first study on the researcher's knowledge that dealt with the relationship between the characteristics of information technology and knowledge management processes in the Arab Potash Company.

\section{Research Methodology}

Descriptive approach was based in the study; which stems from studying the theoretical dimensions of the impact of the characteristics of information technology on knowledge processes defined in the Arab Potash Company, And through the survey office in order to build the theoretical framework, and look at previous studies; study relied on field method using a questionnaire to collect data from a study community in order to answer the study questions and test hypothesis.

\subsection{Research Hypothesis}

In order to answer the research questions of this study we will develop the following hypotheses:

H1: there is no statistically significant impact at the level of significance $(0.05 \geq \alpha)$ of the characteristics of information technology (hardware, software, security, and Usability) on knowledge management processes in the Arab Potash Company.

H2: there is no statistically significant impact at the level of significance $(0.05 \geq \alpha)$ of the characteristics of information technology (hardware, software, security, and Usability) on knowledge creation as a dimension of knowledge management processes in the Arab Potash Company.

H3: there is no statistically significant impact at the level of significance $(0.05 \geq \alpha)$ of the characteristics of information technology (hardware, software, security, and Usability) on knowledge Acquiring as a dimension of knowledge management processes in the Arab Potash Company.

H4: there is no statistically significant impact at the level of significance $(0.05 \geq \alpha)$ of the characteristics of information technology (hardware, software, security, and Usability) on Knowledge Organizing as a dimension of knowledge management processes in the Arab Potash Company.

H5: there is no statistically significant impact at the level of significance $(0.05 \geq \alpha)$ of the characteristics of information technology (hardware, software, security, and Usability) on Knowledge sharing as a dimension of knowledge management processes in the Arab Potash Company.

H6: there is no statistically significant impact at the level of significance $(0.05 \geq \alpha)$ of the characteristics of information technology (hardware, software, security, and Usability) on Knowledge implementation as a dimension of knowledge management processes in the Arab Potash Company.

\subsection{Research Model}

Independent variables

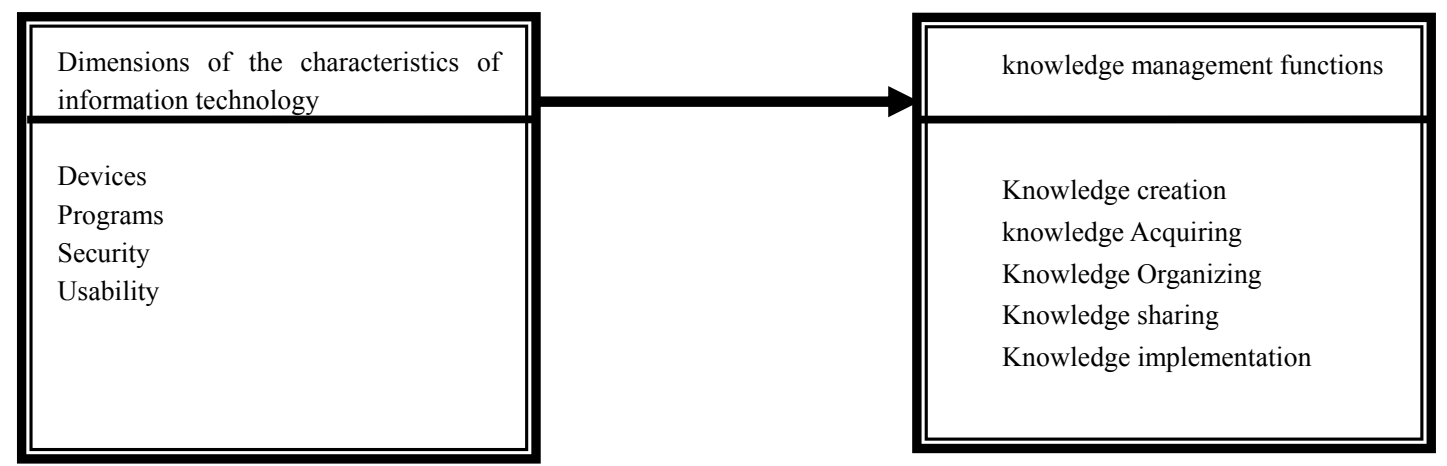

Figure 1.

\subsection{The Research Population}

Research Population Represents the top and middle management personnel in the Arab Potash Company, It also includes some executive departments relevant to the telecommunications unit, information technology, 
marketing departments, production supplies and engineering development department, quality and technical department, and the Department of Training and Developmentm Where the number of employees (418) male and female. Questionnaires were distributed to members of the study community, (339) questionnaire where collected back, representing (81.1\%) of the total community, (3) questionnaires were excluded for non-suitability for analysis, Bringing the number of valid questionnaires for analysis (336) questionnaire, and so (80.4\%) of the study which is valid for the purposes of scientific research.

Looking at Table 1 shows that (59.8\%) are first university degree holders (Bachelor), also found that (23.8\%) are diploma holders, while those who hold higher diploma counted the percentage of (16.4\%).

For age variable, the majority of respondents (34.2\%) were from the age group (31-40 years old), (29.8\%) of the respondents are from age group (41-50 years old), (18.8\%) of respondents are of the age group (30 years and below), while (17.3\%) of the respondents are of age group (51 years and over). With respect to an experience variable, most respondents (31.1\%) were with Class of Service (11 -15 years) while respondents with a class of service (16 years and above) less category accounted for $(20.5 \%)$.

As for gender, most members of the study community were male, accounting proportion $(61.6 \%)$ while the percentage of females (38.4\%) of the total members of the study and this reflects the reality of the labor force in the organizations of Jordan, as male ratio always exceed females. With regard to marital status, most members of the study population were married, they formed a percent of $(71.1 \%)$ while the percentage of single category (28.9\%) of the total study sample.

Table 1. Description of Characteristics of Study Community

\begin{tabular}{llll}
\hline Variable & Variable categories & No. & Percentage \\
\hline Education & Diploma & 80 & $\% 23.8$ \\
& Bachelor & 201 & $\% 59.8$ \\
& Higher Diploma & 55 & $\% 16.4$ \\
\hline Age & $30-$-ess yrs & 63 & $\% 18.8$ \\
& $40-31$ & 115 & $\% 34.2$ \\
& $50-41$ & 100 & $\% 29.8$ \\
\hline Experience & $51-$ more & 58 & $\% 17.3$ \\
& 5 -less yrs & 78 & $\% 23.2$ \\
& $6-10$ & 88 & $\% 26.2$ \\
& $11-15$ & 101 & $\% 30.1$ \\
\hline \multirow{2}{*}{ Gender } & $15-$ morw & 69 & $\% 20.5$ \\
\hline \multirow{2}{*}{ Marital Status } & Male & 207 & $\% 61.6$ \\
& Female & 129 & $\% 38.4$ \\
\hline
\end{tabular}

\subsection{Study Tool}

Study tool was developed in proper manner and based on previous studies also consulting experts and competence, and is composed of three parts (Supplement No. 1):

Part I: devoted to the collection of personal \& functional data and for workers, and includes (gender, educational qualification, age, marital status, experience)

Part II: It consists of (20) paragraph measure variable study independent properties of information technology, has also been developing this part depending on the study (Saadi, 2010; Aasan \& Ani, 2008; Albuhaisi, 2006; Altaweel \& Rashid, 2005; Almashragi, 2004; Omari, 2004), where it was modified to suit the nature of the workers tasks in the study community, and includes four dimensions subsidiary to measure the characteristics of information technology, such as: (hardware; posed in questions 1-5, programe; posed in questions 6-10, security; posed in questions 11-15, and Usability; posed in questions 16-20).

Part III: contains paragraphs aimed to determine the dimensions and knowledge management processes, construction of these paragraphs has been build upon examine each of (Hassan, 2008; Almtani, 2008; Atwi, 2008; Ghamdi, 2008; Majali, 2009; Aguiar, 2009) This part includes five subset measures measuring knowledge management processes, such as: (knowledge creation; posed in questions 21-25, the acquisition of knowledge; posed in questions 26-30, knowledge implementation; posed in questions 31-35, the knowledge sharing; posed in 
questions 36-41, and organize knowledge which is posed in questions 42-46)

\subsection{Tool Sincerity}

The questionnaire was presented to a number of professors with expertise of faculty members in Jordanian universities, to verify the sincerity of the questionnaire paragraphs, and their notes were taken in consideration, And rework some of the paragraphs, and make the required adjustments accurately to achieve a balance between the contents of the questionnaire and paragraphs, Moreover the questionnaire was presented on a test sample of (30) employees from outside the study sample in order to identify the degree of sincerity of study tool, and they had expressed a desire to interact with the paragraphs which confirmed sincerity.

\subsection{Stability of Study Tool}

Stability has been confirmed using the method of testing and re-testing (test-retest) And distributed to exploratory sample consisting of (25) from outside the study sample, and a difference of two weeks between the 2 application, Where the stability coefficient were extract of the tool in its final collective formula, and for each dimension of the study, The results were as shown in Table 2 as follows:

Table 2. Value of stability coefficient for internal consistency of the instrument as a whole and each dimension of the study

\begin{tabular}{|c|c|c|c|c|}
\hline \multirow{2}{*}{ Dimension } & \multirow{2}{*}{ Dimension } & \multirow{2}{*}{ Paragraph Sequence } & \multicolumn{2}{|c|}{ stability coefficient } \\
\hline & & & Test-Retest & Alpha \\
\hline 1 & Devices & $5-1$ & 0.88 & 0.87 \\
\hline 2 & Software & $10-6$ & 0.85 & 0.86 \\
\hline 3 & Security & $15-11$ & 0.86 & 0.90 \\
\hline 4 & Usability & $20-16$ & 0.87 & 0.89 \\
\hline $4-1$ & Characteristics of information technology & $20-1$ & 0.91 & 0.90 \\
\hline 1 & Knowledge creation & $25-21$ & 0.88 & 0.85 \\
\hline 2 & Knowledge Acquiring & $30-26$ & 0.89 & 0.86 \\
\hline 3 & Knowledge organizing & $35-31$ & 0.92 & 0.89 \\
\hline 4 & knowledge sharing & $41-36$ & 0.87 & 0.84 \\
\hline 5 & Knowledge implementation & $46-42$ & 0.83 & 0.80 \\
\hline $5-1$ & Knowledge Management processes & $46-21$ & 0.92 & 0.91 \\
\hline
\end{tabular}

\subsection{Statistical Treatments}

To answer questions about the study and test the validity of hypotheses. Descriptive Statistic Analytical methods (by using SPSS. 16) were used.

1- Descriptive statistic Measures: To describe the characteristics of the study sample by percentages.

2- Multiple Regression Analysis: To test the validity of the model study, the effect of the independent variable on the dependent variable.

3- Stepwise Multiple Regression Analysis: To test the entry of independent variables in the equation of predict the dependent variable.

4- Variance Inflation Factory (VIF) \& Tolerance: making sure that there is no high correlation between independent variables (Multi co- linearity).

5- Testing Skewness: making sure that data is following (Normal Distribution)

6- Cronbach's Alpha Formula: For internal consistency to check the stability of the study tool.

\section{Data Analysis and Hypotheses Testing}

\subsection{Testing Hypothesis}

Before using regression analysis to test hypotheses, some tests have been conducted in order to insure that data are valid for regression analysis hypotheses. For the hypothesis, multi-collinearity between independent variables must not be found, the researcher conducted Variance Infation Factor (VIF) and Tolerance test for each variables of independent variables. Table 3 indicates that if (VIF) for the variable over (10) and the value of acceptable variation was less than (0.05), it could say that this variable has high correlation with other independent variables which causes a problem to regression analysis. Testing Multicollinearity between variables was based on this rule. From the table 9, which contains values of (VIF) and Tolerance for each variable, we can 
see that (VIF) value for all variables was less than (10) and ranged $(1.412-2.874)$; also we can notice that variation value for all variables was more than $(0.05)$ and ranged $(0.534-0.708)$, so we can say that there is no serious problem related to existence multicollinearity between independent variables.

Table 3. Variance inflation factor test and allowable variation coefficient sprains

\begin{tabular}{llll}
\hline Variables & Tolerance & (VIF) & Skewness \\
\hline Devices & 0.566 & 1.768 & 0.370 \\
Software & 0.534 & 1.874 & 0.210 \\
Security & 0.708 & 1.412 & 0.266 \\
Usability & 0.698 & 1.433 & 0.249 \\
\hline
\end{tabular}

In order to investigate the assumption normal distribution of the data has been invoked to calculate the value of (Skewness) of variables, as shown in Table 3, the value of (Skewness) for all study variables were less than (1), so we can say that there is no real problem concerning the normal distribution to study data.

Table 4. Analysis of variance to ensure validity of the model to test hypothesis

\begin{tabular}{|c|c|c|c|c|c|c|c|}
\hline Dependent Variable & Source & Freedom Level & $\mathrm{R}^{2}$ & Sum of squares & Average squares & Value of $F$ & Level F \\
\hline \multirow[t]{2}{*}{ Functions of K.M } & Regression & 4.331 & 0.487 & 49.115 & 12.279 & $* 78.577$ & 0.000 \\
\hline & Error & & & 51.723 & 0.156 & & \\
\hline \multirow[t]{2}{*}{ Knowledge creation } & Regression & 4.331 & 0.48 & 46.190 & 11.548 & $* 76.488$ & 0.000 \\
\hline & Error & & & 49.972 & 0.151 & & \\
\hline \multirow[t]{2}{*}{ Knowledge Acquiring } & Regression & 4.331 & 0.396 & 48.694 & 12.174 & $* 54.304$ & 0.000 \\
\hline & Error & & & 74.202 & 0.224 & & \\
\hline \multirow[t]{2}{*}{ Knowledge organizing } & Regression & 4.331 & 0.403 & 45.667 & 11.417 & $* 55.824$ & 0.000 \\
\hline & Error & & & 67.691 & 0.205 & & \\
\hline \multirow[t]{2}{*}{ Knowledge sharing } & Regression & 4.331 & 0.494 & 49.606 & 12.401 & $* 80.788$ & 0.000 \\
\hline & Error & & & 50.811 & 0.154 & & \\
\hline \multirow[t]{2}{*}{ Knowledge implementation } & Regression & 4.331 & 0.388 & 57.501 & 14.375 & $* 52.437$ & 0.000 \\
\hline & Error & & & 90.742 & 0.274 & & \\
\hline
\end{tabular}

Note: *Statistically significant at the level $(\alpha \leq 0.05)$.

Table 4 explains the validity of the model to test hypothesis, and due to the high value of calculated (F) for Tabulated value at the level of significance $(0.05 \geq \alpha)$ and degrees of freedom $(4,331)$, where the characteristics of information technology interprets $(48.7 \%)$ of variation in dimension of (the knowledge management processes), also explain (48\%) of the variance in dimension (knowledge creation), it explain $(39.6 \%)$ of the variance in (Knowledge Acquiring), and interpreted the characteristics of information technology (40.3\%) of variation in (knowledge organizing), the results explain (49.4\%) of the variance in dimension of (sharing of knowledge), and explore (38.8\%) of the variance in (Knowledge implementation), this confirms the role and impact of information technology in the interpretation of the Knowledge Management processes. Accordingly, we can test hypothesis of the study.

H1: There is no statistically significant impact at the level of significance $(0.05 \geq \alpha)$ of information technology (hardware, software, security, and Usability) on knowledge management processes in the Arab Potash Company.

Table 5. Results of multiple regression analysis to test the impact of information technology on knowledge management processes in the Arab Potash Company

\begin{tabular}{llllll}
\hline Characteristics of information technology & B & Standard error & Beta & Calculated value of $t$ & Level of significance t \\
\hline Devices & 0.222 & 0.054 & 0.214 & $4.093^{*}$ & 0.000 \\
Software & 0.220 & 0.051 & 0.231 & $4.282^{*}$ & 0.000 \\
Security & 0.238 & 0.059 & 0.190 & $4.058^{*}$ & 0.000 \\
Usability & 0.274 & 0.050 & 0.257 & $5.463^{*}$ & 0.000 \\
\hline
\end{tabular}

Note: *Statistically significant at the level $(\alpha \leq 0.05)$.

It appears from the results presented in Table 5, and follow-up values test ( $\mathrm{t}$ ) that the variables of the following (hardware, software, security, and Usability) have an impact on Knowledge Management processes in the Arab 
Potash Company, the values of $(\mathrm{t})$ is $(4.093,4.282,4.058,5.463)$ respectively, at the level of significance $(\mathrm{a} \leq 0.05)$. So we reject the null Hypothesis, which states that: No effect statistically significant at the level of $(0.05 \geq \alpha)$ to the characteristics of information technology (hardware, software, security, and Usability) on the knowledge management processes in the Arab Potash Company.

Table 6. Results of multiple regression analysis gradual Stepwise Multiple Regression to predict the knowledge management processes through the characteristics of information technology as independent variables

\begin{tabular}{llll}
\hline entry Order of independent elements in the equation to predict & Value $\mathrm{R}^{2}$ & Calculated value of $\mathrm{t}$ & Level of significance $\mathrm{t}^{*}$ \\
\hline Usability & 0.333 & $* 6.002$ & 0.000 \\
Software & 0.429 & $* 5.784$ & 0.000 \\
Devices & 0.462 & $* 4.932$ & 0.000 \\
Security & 0.485 & $* 4.426$ & 0.000 \\
\hline
\end{tabular}

Note: *Statistically significant at the level $(\alpha \leq 0.05)$.

When analyzing Stepwise Multiple Regression to determine the importance of each independent variable to contribute to the mathematical model, which represents the impact of the characteristics of information technology (hardware, software, security, and Usability) on the knowledge management processes in the Arab Potash Company, table 6 showed us that the dimensions of Usability has come first, and explained amount (33.3\%) of the variance in the dependent variable, then programs where interpreted with the dimension of Usability $(42.9 \%)$ of the variance in the dependent variable, the hardware where interpreted with former variables $(46.2 \%)$ of the variance in the dependent variable, and the dimension of security comes finally which interpreted with previous variables amount $(48.5 \%)$ of the variance in the knowledge management processes in the Arab Potash Company as a dependent variable.

H2: There is no statistically significant impact at the level of significance $(0.05 \geq \alpha)$ of the characteristics of information technology (hardware, software, security, and Usability) on knowledge creation as a dimension of knowledge management processes in the Arab Potash Company.

Table 7. Results of multiple regression analysis to test the impact of information technology on knowledge creation as a dimension of knowledge management processes in the Arab Potash Company

\begin{tabular}{llllll}
\hline the dimensions of the characteristics of IT & B & Standard error & Beta & Calculated value of $(\mathrm{T})$ & Level of significance $(\mathrm{t})$ \\
\hline Hardware & 0.160 & 0.053 & 0.158 & $* 3.001$ & 0.003 \\
Programs & 0.226 & 0.050 & 0.243 & $* 4.485$ & 0.000 \\
Security & 0.310 & 0.058 & 0.254 & $* 5.388$ & 0.000 \\
Usability & 0.243 & 0.049 & 0.233 & $* 4.917$ & 0.000 \\
\hline
\end{tabular}

Note: *Statistically significant at the level $(\alpha \leq 0.05)$.

Table 7 indicates that the variables of IT (hardware, software, security, and Usability) have an impact on knowledge creation as a dimension of Knowledge Management processes in the Arab Potash Company, where calculated values of $(\mathrm{t})$ is $(3.001 ، 4.485 ، 5.388,4.917)$ respectively, at the level of significance $(\mathrm{a} \leq 0.05)$. Therefore we reject the null Hypothesis, which states that: there is no statistical significant impact at the level $(a \leq 0.05)$ to the characteristics of information technology (hardware, software, security, and Usability) in knowledge creation as a dimension of Knowledge Management processes in the Arab Potash Company.

Table 8 . The results of stepwise multiple regression to predicate the knowledge creation through the dimensions of the characteristics of IT as independent variables

\begin{tabular}{llll}
\hline $\begin{array}{l}\text { Order entry independent elements } \\
\text { in the equation of prediction }\end{array}$ & $\begin{array}{l}\mathrm{R}^{2} \text { value } \\
\text { The coefficient of determination }\end{array}$ & Calculated value of $(\mathrm{t})$ & Level of significance (t) \\
\hline Security & 0.332 & $* 6.374$ & 0.000 \\
Usability & 0.414 & $* 5.873$ & 0.000 \\
Programs & 0.466 & $* 4.587$ & 0.000 \\
Devices & 0.477 & $* 3.794$ & 0.000 \\
\hline
\end{tabular}

Note: *Statistically significant at the level $(\alpha \leq 0.05)$.

As shown in Table 8, the dimension security occupied the first level, and explained a amount (33.2\%) of the 
variance in the dependent variable, the Usability comes next which interpreted with the dimension of Security (41.4\%) of the variance in the dependent variable, the programs ecubied the third level which interpreted $(46.6 \%)$ of the variance in the dependent variable, finally the dimension of devices, it interpreted with previous variables amounte $(47.7 \%)$ of the variance in knowledge creation dimensions of knowledge management processes in the Arab Potash Company as the dependent variable.

H3: there is no statistically significant impact at the level of significance $(0.05 \geq \alpha)$ of information technology (hardware, software, security, and Usability) on knowledge Acquiring as a dimension of knowledge management processes in the Arab Potash Company.

Table 9. The results of analyzing of stepwise Multiple Regression

\begin{tabular}{llllll}
\hline Characteristics of information technology & B & Standard error & Beta & Calculated value of $(\mathrm{t})$ & Level of significance $(\mathrm{t})$ \\
\hline Devices & 0.277 & 0.065 & 0.241 & $4.252^{*}$ & 0.000 \\
Programs & 0.187 & 0.062 & 0.177 & $3.033^{*}$ & 0.003 \\
Security & 0.208 & 0.070 & 0.151 & $2.970^{*}$ & 0.003 \\
Usability & 0.273 & 0.060 & 0.232 & $4.539^{*}$ & 0.000 \\
\hline
\end{tabular}

Note: *Statistically significant at the level $(\alpha \leq 0.05)$.

The above table elucidates that the overall average impact of (hardware, software, security, and Usability) on the Acquiring as a dimension of knowledge management processes in the Arab Potash Company is high, where the calculated value of (t) $(4.252,3.033,2.970,4.539)$ respectively, at the level of significance $(a \leq 0.05)$. Therefore we reject the null Hypothesis, which states that: which states that: No significant statistically effect at the level of $(0.05 \geq$ a) of the characteristics of information technology (hardware, software, security, and Usability) on knowledge Acquiring as a dimension of knowledge management processes in the Arab Potash Company.

Table 10 .

\begin{tabular}{llll}
\hline $\begin{array}{l}\text { Order entry independent elements in the } \\
\text { equation of prediction }\end{array}$ & $\begin{array}{l}\mathrm{R}^{2} \text { value } \\
\text { The coefficient of determination }\end{array}$ & $\begin{array}{l}\text { Calculated value of } \\
(\mathrm{t})\end{array}$ & $\begin{array}{l}\text { Level of significance } \\
(\mathrm{t})\end{array}$ \\
\hline Usability & 0.277 & $* 5.863$ & 0.000 \\
Devices & 0.349 & $* 5.018$ & 0.000 \\
Programs & 0.380 & $* 3.472$ & 0.000 \\
Security & 0.392 & $* 3.261$ & 0.000 \\
\hline
\end{tabular}

Note: *Statistically significant at the level $(\alpha \leq 0.05)$.

Table 10 indicates that the Usability dimension has ranked first, and explained the amount $(27.7 \%)$ of the variance in the dependent variable, the hardware dimension comes next where interpreted $(34.9 \%)$ of the variance in the dependent variable, the programs variable occupied the third level, it explained the amount (38\%) of the variance in the dependent variable, finally the security where interpreted amount $(39.2 \%)$ of the variance in knowledge acquiring variable.

H4: There is no statistically significant impact at significance level $(0.05 \geq a)$ of information technology (hardware, software, security, and Usability) on knowledge implementation as a dimension of knowledge management processes in the Arab Potash Company.

Table 11

\begin{tabular}{llllll}
\hline Characteristics of information technology & $\mathrm{B}$ & Standard error & Beta & Calculated value of $(\mathrm{t})$ & Level of significance $(\mathrm{t})$ \\
\hline Devices & 0.230 & 0.062 & 0.209 & $* 3.700$ & 0.000 \\
Programs & 0.241 & 0.059 & 0.238 & $* 4.109$ & 0.000 \\
Security & 0.199 & 0.067 & 0.150 & $* 2.971$ & 0.003 \\
Usability & 0.236 & 0.057 & 0.209 & $* 4.104$ & 0.000 \\
\hline
\end{tabular}

Note: *Statistically significant at the level $(\alpha \leq 0.05)$.

Table 11 indicates that the variables of IT (hardware, software, security, and Usability) have an impact on knowledge implementation as a dimension of Knowledge Management processes in the Arab Potash Company, where calculated values of (t) is $(3.70,4.109,2.971,4.104)$ respectively, at the level of significance $(a \leq 0.05)$.Therefore we reject the null Hypothesis, which states that: No statistically significant effect at the level 
of $(0.05 \geq a)$ to the characteristics of information technology (hardware, software, security, and Usability) in knowledge implementation as a dimension of knowledge management processes in the Arab Potash Company.

Table 12 .

\begin{tabular}{llll}
\hline $\begin{array}{l}\text { Order entry independent elements } \\
\text { in the equation of prediction }\end{array}$ & $\begin{array}{l}\mathrm{R}^{2} \text { value } \\
\text { The coefficient of determination }\end{array}$ & Calculated value of $(\mathrm{t})$ & Level of significance (t) \\
\hline Programs & 0.290 & $5.210^{*}$ & 0.000 \\
Usability & 0.357 & $4.596^{*}$ & 0.000 \\
Devices & 0.387 & $3.994^{*}$ & 0.000 \\
Security & 0.401 & $3.197^{*}$ & 0.002 \\
\hline
\end{tabular}

Note: *Statistically significant at the level $(\alpha \leq 0.05)$.

As shown in table 12, the programs factor ranked first, explained the amount $(29 \%)$ of the variance in the dependent variable, then followed by usability where interpreted $(35.7 \%)$ of the variance in the dependent variable, the hardware variable occupied the third level, explained the amount $(38.7 \%)$ of the variance in the dependent variable, finally the security variable with the rate of $(40.1 \%)$ of the variance in knowledge implementation as a dependent variable.

H5: There is no statistically significant impact at level $(0.05 \geq a)$ of information technology (hardware, software, security, and Usability) on the knowledge sharing as a dimension of knowledge management processes in the Arab Potash Company.

Table 13. The results of analyzing gradual Stepwise Multiple Regression to test the impact of IT on knowledge sharing as a dimension of knowledge management processes in the Arab Potash Company

\begin{tabular}{llllll}
\hline Characteristics of information technology & B & Standard error & Beta & Calculated value of $(\mathrm{t})$ & Level of significance $(\mathrm{t})$ \\
\hline Devices & 0.133 & 0.054 & 0.128 & $2.462^{*}$ & 0.014 \\
Programs & 0.268 & 0.051 & 0.282 & $5.261^{*}$ & 0.000 \\
Security & 0.231 & 0.058 & 0.185 & $3.975^{*}$ & 0.003 \\
Usability & 0.318 & 0.050 & 0.299 & $6.390^{*}$ & 0.000 \\
\hline
\end{tabular}

Note: *Statistically significant at the level $(\alpha \leq 0.05)$.

It appears from the results presented in Table 13, the variable of IT (hardware, software, security, and Usability) have an impact on knowledge sharing in the Arab Potash Company, the values of (t) is (2.462, 5.261, 3.975, 6.390) respectively, at the level of significance $(a \leq 0.05)$. So we reject the null Hypothesis, which states that: No significant statistical effect at the level of $(0.05 \geq a)$ to the characteristics of information technology (hardware, software, security, and Usability) in the knowledge sharing as a dimension of knowledge management processes in the Arab Potash Company.

Table 14. The results of analyzing gradual Stepwise Multiple Regression to predict the knowledge sharing through the dimensions of the characteristics of IT as independent variable

\begin{tabular}{llll}
\hline $\begin{array}{l}\text { Order entry independent elements } \\
\text { in the equation of prediction }\end{array}$ & $\begin{array}{l}\mathrm{R}^{2} \text { value } \\
\text { The coefficient of determination }\end{array}$ & Calculated value of $(\mathrm{t})$ & Level of significance ( $\mathrm{t})$ \\
\hline Usability & 0.351 & $* 7.260$ & 0.000 \\
Programs & 0.457 & $* 6.991$ & 0.000 \\
Security & 0.485 & $* 4.228$ & 0.000 \\
Devices & 0.491 & $* 2.746$ & 0.009 \\
\hline
\end{tabular}

Note: *Statistically significant at the level $(\alpha \leq 0.05)$.

Table 14 explain that the respondents' perceptions level toward the impact of information technology (hardware, software, security, and Usability) in the knowledge sharing as a dimension of knowledge management processes in the Arab Potash Company. The usability attained high ratio with average (35.1) of the variance in the dependent variable, followed by programs with average (45.7) of the variance in the dependent variable, while the security came in the third rank with average (48.5) of the variance in the dependent variable, Finally devices came in the last level with average (49.1) of the variance in the dependent variable.

H6: there is no statistically significant impact at level $(0.05 \geq a)$ to the characteristics of information technology 
(hardware, software, security, and Usability) in organizing of knowledge as a dimension of knowledge management processes in the Arab Potash Company.

Table 15 .

\begin{tabular}{llllll}
\hline Characteristics of information technology & B & Standard error & Beta & Calculated value of $(\mathrm{t})$ & Level of significance $(\mathrm{t})$ \\
\hline Devices & 0.313 & 0.072 & 0.248 & $* 4.342$ & 0.000 \\
Programs & 0.178 & 0.068 & 0.154 & $* 2.613$ & 0.009 \\
Security & 0.240 & 0.078 & 0.158 & $* 3.094$ & 0.002 \\
Usability & 0.302 & 0.066 & 0.234 & $* 4.544$ & 0.000 \\
\hline
\end{tabular}

Note: *Statistically significant at the level $(\alpha \leq 0.05)$.

The above table elucidates that the overall average impact of (hardware, software, security, and Usability) on the organizing of knowledge as a dimension of knowledge management processes in the Arab Potash Company is high, where the calculated value of $(\mathrm{t})$ is $(4.342,2.613,3.094,4.544)$ respectively, at the level of significance $(a \leq 0.05)$. Therefore we reject the null Hypothesis, which states that: No statistically significant effect at the level of $(0.05 \geq a)$ to the characteristics of information technology (hardware, software, security, and Usability) in the organizing of knowledge as a dimension of knowledge management processes in the Arab Potash Company.

Table 16. The results of analyzing gradual Stepwise Multiple Regression to predict the knowledge organizing through the dimensions of the characteristics of IT as independent variable

\begin{tabular}{llll}
\hline $\begin{array}{l}\text { Order of entry of independent elements } \\
\text { in the equation of predict }\end{array}$ & $\begin{array}{l}\mathrm{R}^{2} \text { value } \\
\text { The coefficient of determination }\end{array}$ & $\begin{array}{l}\text { Calculated value of } \\
(\mathrm{t})\end{array}$ & $\begin{array}{l}\text { Level of significance } \\
(\mathrm{t})\end{array}$ \\
\hline Usability & 0.273 & $* 5.014$ & 0.000 \\
Devices & 0.344 & $* 4.973$ & 0.000 \\
Security & 0.375 & $* 3.863$ & 0.000 \\
Programs & 0.383 & $* 2.919$ & 0.006 \\
\hline
\end{tabular}

Note: *Statistically significant at the level $(\alpha \leq 0.05)$.

Table 16 explain that the respondents' perceptions level toward the impact of information technology (hardware, software, security, and Usability) in the knowledge sharing as a dimension of knowledge management processes in the Arab Potash Company is high. So the usability attained high ratio with average (27.3) of the variance in the dependent variable, followed by hardware with average (34.3) of the variance in the dependent variable, while the security came in the third rank with average (37.5) of the variance in the dependent variable, Finally devices came in the last level with average (38.3) of the variance in the dependent variable.

\section{Research Findings and Results}

\subsection{Discussion of the Findings}

The results indicated that the characteristics of information technology interprets $(48.7 \%)$ of the variance in the dimension of (knowledge management processes), also explain $(48 \%)$ of the variance in the dimension of (knowledge creation), either explain (39.6\%) of the variance in the dimension of (knowledge acquisition), and interpreted the characteristics of information technology $(40.3 \%)$ of the variance in the dimension of (knowledge implementation), it also explain (49.4\%) (38.8) of the variance in the dimension of (knowledge sharing), and (organizing of knowledge) respectively, this result explains that successful organizations in order to ensure its survival, and continuity of its being strong and effective should not stop at efficiency in the sense to be convinced to do their work properly, but knowledge implementation and technology are to be the hallmarks of the performance of their services. The sense of employees of the availability of knowledge processes is one of the stimulating effects on finding proactive organizations to ensure the achievement of the interest of the organization and the individual together. This results also explain that the availability of dimensions of knowledge management helps to optimal use of modern information systems, facilitate administrative procedures, increase efficiency of their employees, improve output, save time and money; through the availability of the necessary equipment for the implement of this concept in the company, the availability of specialists, IT required infrastructure, the availability of equipment and the necessary qualified human resources, clear strategic plans, and an extensive database, all of this can contribute to the effectiveness of organizational development. The availability of acceptable degrees of knowledge indicators among workers is one of the most important pillars that help to use systematic knowledge management. 
The results of this study agree with the study of (Almtani, 2008) which its findings indicated that the degree of application of knowledge management in higher education institutions in the Sultanate of Oman was moderate in all knowledge management processes that were the areas of study, and are also consistent with a study of (Al atwi, 2008) that its results indicated that the knowledge management processes according to the perceptions of the study sample with a medium level.

The results showed that the variables (hardware, software, security, and Usability) have an impact on knowledge management processes in the Arab Potash Company, it indicates that the dimension of Usability has ranked first, and explained amount (33.3\%) of the variance in the dependent variable, but the dimension of Programs comes next which interpreted $(42.9 \%)$ of the variance in the dependent variable, while the hardware came in the third rank with average $(46.2 \%)$ of the variance in the dependent variable, finally the dimension of security came in the last level with average (48.5\%) of variation in knowledge management processes in the Arab Potash Company. This result explains that the availability of the characteristics of information technology in the Arab Potash Company will improve the using of knowledge, helps the use of modern information systems to facilitate administrative procedures, increase efficiency of their employees, improve output, and saves time and money. The integration of these systems is designed to more understanding and accurate interpretation of management information, ensuring integration and removes the contradiction of the information obtained by the decision maker from external sources and those obtained from internal sources, also it provides the organization with methods that enable them to draw the necessary plans to strengthen the knowledge management processes to achieve the primary and secondary objectives through the use of human resources and information.

The results showed that the impact of information technology (hardware, software, security, and Usability) in knowledge creation as a dimension of knowledge management processes in the Arab Potash Company, so dimension of Security has ranked first, with average (33.2\%) of the variance in the dependent variable, followed by dimension of Usability with rate $(41.4 \%)$ of the variance in the dependent variable, then the dimension of Programs with average $(46.6 \%)$ of the variance in the dependent variable, finally the dimension of devices which attained $(47.7 \%)$ of the variance in creation of knowledge as a dimension of knowledge management processes in the Arab Potash Company as the dependent variable. The possible explanation of this is that the used devices are characterized, modern, easy to use, easy to learn, and leading to the rapid acceptance and adoption by the workers, thus their use helps them perform their functional duties with more efficiency and effectiveness.

The results showed that the impact of the characteristics of information technology (hardware, software, security, and Usability) in the acquisition of knowledge as a dimension of knowledge management processes in the Arab Potash Company, the dimension of usability came in the first rank with average $(27.7 \%)$ of variation in the dependent variable, the dimension of hardware came in next level with average $(34.9 \%)$ of the variance in the dependent variable, then followed by the dimension of Programs with average (38\%) of the variance in the dependent variable, finally the dimension of Security with rate $(39.2 \%)$ of the variance in the acquisition of knowledge as a dependent variable. This result also explains that the availability of dimensions the characteristics of information technology in organizations is one of stimulating effects on strengthening the knowledge management processes, so the availability of these dimensions contribute to the domination of interaction and dialogue among individuals, the existence of cooperation and harmony among them and the administration, giving the opportunity to grow , develop, achieve the aspirations of individual, and facilitating ways and methods of work, in order to ensure benefit from the energy and potential of individuals and employees of the organization; to achieve the interest of the organization and the individual together, this result also interpreted that the employees need to create a consensus on the vision and mission of the organization, the values and goals that it seeks to achieve. When clarifying the vision and mission of the Organization for workers, they undoubtedly feel possessing the ability to act freely in their work instead of waiting for orders and instructions

The results indicates that the impact of the characteristics of information technology (hardware, software, security, and Usability) in knowledge implementation as a dimension of knowledge management processes in the Arab Potash Company, so the dimension of Programs came firstly with rate $(29 \%)$ of the variance in the dependent variable, followed by dimension of Usability with average $(35.7 \%)$ of the variance in the dependent variable, while the dimension of hardware came in third level with average $(38.7 \%)$ of the variance in the dependent variable, finally the dimension of Security with average $(40.1 \%)$ of the variance in knowledge implementation as a dependent variable. This result can explain that the Arab Potash Company is keen to use technology in most of its business to achieve speed in the performed work and access to appropriate information using devices and modern networks achieving the purpose of its existence through the adoption of the modern entrances of organizational restructuring, and the use of teams of different involving workers from All 
departments and management levels, to facilitate the use of knowledge, coordination and exchange of information on the internal and external environment.

The results showed the presence of the impact of the characteristics of information technology (hardware, software, security, and Usability) in the knowledge sharing as a dimension of functions of the knowledge management in the Arab Potash Company, the dimension of Usability has ranked first, and explained what amount $(35.1 \%)$ of variation in the dependent variable, and then comes the dimension of Programs which interpreted with the dimension of Usability $(45.7 \%)$ of the variance in the dependent variable, and then comes the dimension of security which interpreted with former variables $(48.5 \%)$ of the variance in the dependent variable, and finally comes the dimension of devices as interpreted with the previous variables rate $(49.1 \%)$ of the variance in the knowledge sharing as the dependent variable. The reason for this may be that the use of information techniques may be reflected on the ways of group thinking. And promote the idea to look at the organization as an integrated unit, and was able to take into account the requirements of recruitment of knowledge. This means that the use of information systems affect the knowledge sharing so as to improve performance, and reduce the time required to complete the work, and provides the information required to perform the work.

The results showed that the impact of the characteristics of information technology (hardware, software, security, and Usability) in organizing knowledge as a dimension of knowledge management processes in the Arab Potash Company, the dimensions came as follow: Usability with average $(27.3 \%)$ of variation in the dependent variable, hardware with average (34.4\%), Security with rate $(37.5 \%)$, finally the dimension of Programs with rate $(38.3 \%)$. This result explains the ability of the Arab Potash Company to organize knowledge to reach: every point in the work, every administrative level through use, share and exchanging ideas and experiences, skills , technology and training programs through formal and informal communication systems to get a flexible distribution point, so that the availability of dimensions of knowledge management in the Arab Potash Company is a positive sign because coping with knowledge is a basic characteristic to successful organizations ,where there is some sort of consensus and harmony among the individual and the organization which provides many benefits such as commitment and motivation, performance and organizational citizenship, as well as increasing commitment, cooperation and loyalty to the organization.

\section{Conclusions and Recommendations}

\subsection{Conclusions}

From the forgoing results, it is advantageous now to identify the most important points that are related to the results of this work as a useful conclusion. These points can be stated as follows: The results indicated that the variables (hardware, software, security, and Usability) have an impact on knowledge management processes in the Arab Potash Company. These results also explain that the availability of dimensions of knowledge management helps to optimal use of modern information systems, facilitate administrative procedures, increase efficiency of their employees, improve output, save time and money. The results explains that the availability of the characteristics of information technology in the Arab Potash Company will improve the using of knowledge, helps the use of modern information systems to facilitate administrative procedures, increase efficiency of their employees, improve output, and saves time and money. The integration of these systems is designed to more understanding and accurate interpretation of management information, ensuring integration and removes the contradiction of the information obtained by the decision maker from external sources and those obtained from internal sources, also it provides the organization with methods that enable them to draw the necessary plans to strengthen the knowledge management processes to achieve the primary and secondary objectives through the use of human resources and information.

The study also explains the ability of the Arab Potash Company to organize knowledge to reach: every point in the work, every administrative level through use, share and exchanging ideas and experiences, skills, technology and training programs through formal and informal communication systems to get a flexible distribution point.

\subsection{Recommendations}

As the results of the study show, we can provide a set of recommendations aimed at enhancing the characteristics of information technology and knowledge management, these recommendations are:

- Reinforcing the characteristics of information technology and knowledge management, through the creation of a database and information systems, which is able to provide management with the necessary quantitative and qualitative information in appropriate time and way at all administrative levels.

- The need to involve employees and users in the process of designing and developing information systems; 
because of their importance in achieving psychological satisfaction and reducing the causes of resistance, raising morale, make them feel their importance in the company, and supplement company with needed qualified and trained competencies to increase the efficiency and effectiveness of these systems, in order to keep pace with successive technological developments in this area.

- The adoption of a management philosophy and organizational methods to support the implement of knowledge management by senior administration, by specifying the adequate financial and human resources ,and instill a flexible and collaborative organizational culture supporting and participating knowledge.

- Providing a level of senior administration commitment embodied in the promotion of a culture of knowledge among employees, also develop their skills and provide a clear strategic vision of the organization, this strengthening effective cognitive abilities of the organization, and the commitment of managers and employees to use knowledge management, and the effectiveness of the organization in the formulating, implementing and evaluating the organization's strategy, in order to create effective knowledge organizations.

- Expanding the scope of the study to include the study of other knowledge management variables and the inclusion of other sectors, and the use of multiple methods to collect information such as content analysis method and the interview, in order to uncover the cognitive system for Arab Management.

\section{References}

Adam, N. b. M. b. M. (2010). The availability of dimensions of knowledge management and its impact on organizational development from the point of view of administrative staff in government hospitals in the city of Riyadh in Saudi Arabia. (unpublished Master thesis). Mutah University, Jordan.

Aguiar, L. (2009). Applying Knowledge Management for Research and Development in the Pharmaceutical Industry. (Ph.D Dissertation). University of phoenix, U.S.A.

Akhavan, P., Jafari, M., \& Fathian, M. (2006). Critical success factors of knowledge management systems: a $\begin{array}{lllll}\text { multi-case analysis. } & \text { European }\end{array}$ http://dx.doi.org/10.1108/09555340610651820

Al Ali, A. S., \& Gundilji, A. Al-O. G. (2006). The gateway to knowledge management. i 1, Dar Al masirah for publication, distribution and printing, Amman, Jordan.

Al Atwi, F. (2008). The availability of knowledge management processes and its impact on organizational effectiveness among workers in the General Organization for Technical and Vocational Education in Saudi Arabia. (unpublished Master thesis). Mutah University, Karak, Jordan.

Alavi, M., \& Wheeler, B. C. (2010). Using IT to Reengineer Business Education: An Exploratory Investigation of Collaborative Telelearning. MIS Quarterly, 19(3), 293-312. http://dx.doi.org/10.2307/249597

Albuhaisi, E. (2006). modern information technology and its impact on management decisions in business organizations - a prospective study of the Palestinian reality. Islamic University Journal (Humanities series), 4(1), 155-177.

Alhotra, Y. (1998). Toward a knowledge Ecology for organization. http//www.Print.com/papers/ecology.htm

Alian, R. (2008). Knowledge Management. Jordan, Amman, Safa House for publication and distribution, i 1.

Almani, A. (2009). Trends of managers in Jordanian ministries centers of the role of knowledge management in functionality: An Empirical Study. Jordan Journal of Business Administration, 5(3), 371.

Almasri, A. M. (2008). modern management, communications - information - decisions. Youth University Foundation, Alexandria, Egypt.

Almtani, A. b. H. b. A. (2008). constructing a model for knowledge management in higher education institutions in the Sultanate of Oman. (unpublished Ph.D thesis). University of Jordan, Amman, Jordan.

Alrezo, H. (2002). The information economy and knowledge management: economic information processing, and working paper submitted to the Fifth Annual Conference, College of Management and Economics Arab Emirates University.

Altawil, A., \& Rashid, H. (2005). The impact of information technology in knowledge management processes: Empirical study in a sample of industrial companies in the province of Ninewa. future research semi-annual scientific journal, 10,11.

Althufairi, N. (2010). The impact of the use of management information systems at the level of functionality: An Empirical Study on the workers and staff in esablishments and government departments in the Eastern Province of Saudi Arabia. (unpublished Master thesis). College of Business Administration, Jordan. 
Alwaleed, B. (2009). Management Information System. Jordan, Amman, Dar Alalam for publication and distribution.

Barnes, S. (2002). Knowledge Management System. (1st ed.) (p. 83). UK, Thomson Learning, Alden Press, Oxford,

Bhatt, G. (2000). Organizing knowledge in the knowledge development cycle. Journal of Knowledge Management, 4(1), 15-26. http://dx.doi.org/10.1108/13673270010315371

Boulhilier, F., \& Kathleen, S. (2002). Understanding knowledge Management and information Management: The Need for an Empirical perspective. Information Research, 8(1).

Canadian, N. A. (2008). the requirements of the application of knowledge management at the Sultan Qaboos University “An Empirical Study”. (unpublished Master thesis). Sultan Qaboos University, Muscat, Sultanate of Oman.

David, N. G. (2009). Management Information Systems And Strategic Performance: The Role Of Top Team Composition. International Journal of Information Management, 29(2), 104-110. http://dx.doi.org/10.1016/j.ijinfomgt.2008.05.009

Dingsoyer, T. (2002). Knowledge Management in Medium sized software Consulting compains. (unpublished Doctoral Thesis). Norwegian university of Science and Technology, Trondheim, Norway /paper/4.html.

Duffy, J. (2000). Knowledge Management: what Every Information professional should know. IMJ, july.

Feliciano, J. L. (2007). The Success Criteria for Implementing Knowledge Management Systems in an Organization. (Ph.D Dissertation). Pace University, (USA).

Gagob, S. Z., \& Alamin, A. W. (2002). A knowledge-based economy: is there a future for developing countries: a case study of Jordan, and a working paper submitted to the Second Annual Scientific Conference. Faculty of Economics and Administrative Sciences, University Zaytoonah.

Ghamdi, N. S. A. (2008). knowledge management as an input for the development of management education for girls in Jeddah. (unpublished Master thesis). Umm Al-Qura University, Makkah.

Hackett, B. (2003). Beyond Knowledge: New Ways to Work and learn. The Conference Board.

Haidari, M. (2008). Computerized management information systems and their impact on the creativity of workers in the telecommunications sector Yemeni. (unpublished Master thesis). faculty of high studies, University of Jordan, Jordan.

Hassan, M. S. A. K. (2008). Proposed administrative educational strategy to increase the added value of using knowledge management in the private schools in the city of Amman. (unpublished Ph.D thesis). University of Jordan, Amman.

Hussain, I. (2010). Knowledge Management For SMEs In Developing Countries. Journal of Knowledge Management Practice, 11(2).

Isan, Salha Abdullah al-Ani, \& Wajiha Thabet. (2008). The role of information technology in the knowledge management in the College of Education at Sultan Qaboos University. Albasaer, 12(1), 59-107.

Khalid, A. (2010). The impact of knowledge management on the effectiveness of decision-making in the Jordanian public shareholding companies, studies. Management Science, 37(2), 114-134.

Kubaisi, A. (2005). knowledge management and organizational development. the modern university office of Alexandria.

Kumar, A., \& Kumar, A. (2006). IT Based KM In Indian Higher Education System: Addressing Quality Concerns And Setting The Priorities Right. Journal of Knowledge Management Practice, 7(3).

Lam, A. (1998). Tacit knowledge, organizational learning and innovation: a societal perspective. Druid Working Paper No. 98-22, Danish Research Unit for Industrial Dynamics, Frederiksberg.

Laudonm, K. C., \& Laudon, J. P. (2007). Management Information Systems: Managing the Digital Firm (10th ed.) (p. 14). New Jersey: Prentice-Hall, Person Education, Upper Saddle River.

Lee, H., \& Liebenau, J. (2000). Temporal effects of Information Systems on Business Processes: Focusing on the Dimentsions of Temporality. International Journal of Information Management, 10(3), 157-185.

Loomis, J. (2000). Knowledge Management and X Generation. Rough Notes, 143(12), 1-28. 
Malhotra, Y. (2003). Measuring knowledge assets of a nation: knowledge systems for development. United Nations Advisory Meeting of the Department of Economic and Social Affairs. Division of Public Administration and Development Management, New York, 4-5.

Malkawi, I. (2007). Knowledge management (practices and concepts). Jordan, Amman, Warraq Foundation for publication and distribution, $\mathrm{i} 1$.

Mitchell, V. L., \& Zmud, R. W. (2009). The Effects of Coupling IT and Work Process Strategies in Redesign Projects. Organization Science: A Journal of the Institute of Management Sciences, 10(4), 424-438. http://dx.doi.org/10.1287/orsc.10.4.424

Momani, K. M. (2005). Trends of managers towards the application of knowledge management in public institutions in Jordan (Case Study). (unpublished Master thesis). University of Jordan, Amman, Jordan.

Najim, A. (2005). Knowledge management: concepts, strategies and processes. Amman, Jordan: Al-Warraq for publication and distribution.

Newkirk, H., Albert, L., \& Alice, J. (2008). The Impact Of Business And IT Change On Strategic Information Systems Alignment. Proceedings For The Northeast Region Decision Sciences Institute (NEDSI), 6(1), 469-474.

Oliver, J. (2008). Knoweledge Management Practices To Support Continuouse Improvement. Journal of Knowledge Management Practice, 9(4).

Omari, G. (2004). Joint use of information technology and knowledge management to achieve a high value to the work of Jordanian commercial banks. (PhD thesis unpublished). Business Administration, Faculty of Management Studies and Finance High, Amman Arab University for Graduate Studies, Jordan.

Pervaiz, K., Ahmed, K. K., Lim, A. Y., \& Loh, E. (2002). Learning Through Knowledge Management. Butterworth-Heinemann.

Quintas, P., Lefere, P., \& Jones, G. (1997). Knowledge Management: A strategic Agenda. Long Range Planning, 30(3), 80-89.

Saadi, I. K. (2010). The impact of the use of information technology on the audit profession in the industrial sector in Jordan: An Empirical Study. Journal of Public Administration, 50(1), 53-83.

Singh, S. (2008). The Development and Investigation of a Conceptual Model to Understand Knowledge Management. (Ph.D. Dissertation). Queen's University, Canada.

Tartarh, S. E. (2006). The impact of computerized management information systems on the functions of human resource management in public institutions in Jordan: An Empirical Study. (unpublished Master thesis). Faculty of high studies, University of Jordan.

Yassin, S. (2007). Knowledge management - systems technology concepts. Jordan, Amman, Curriculum Publishing and Distribution, i 1. 